\title{
Nurses' attitudes and reactions to workplace violence in obstetrics and gynaecology departments in Cairo hospitals
}

N. Samir, ${ }^{1}$ R. Mohamed, ${ }^{1}$ E. Moustafa ${ }^{1}$ and H. Abou Saif ${ }^{2}$

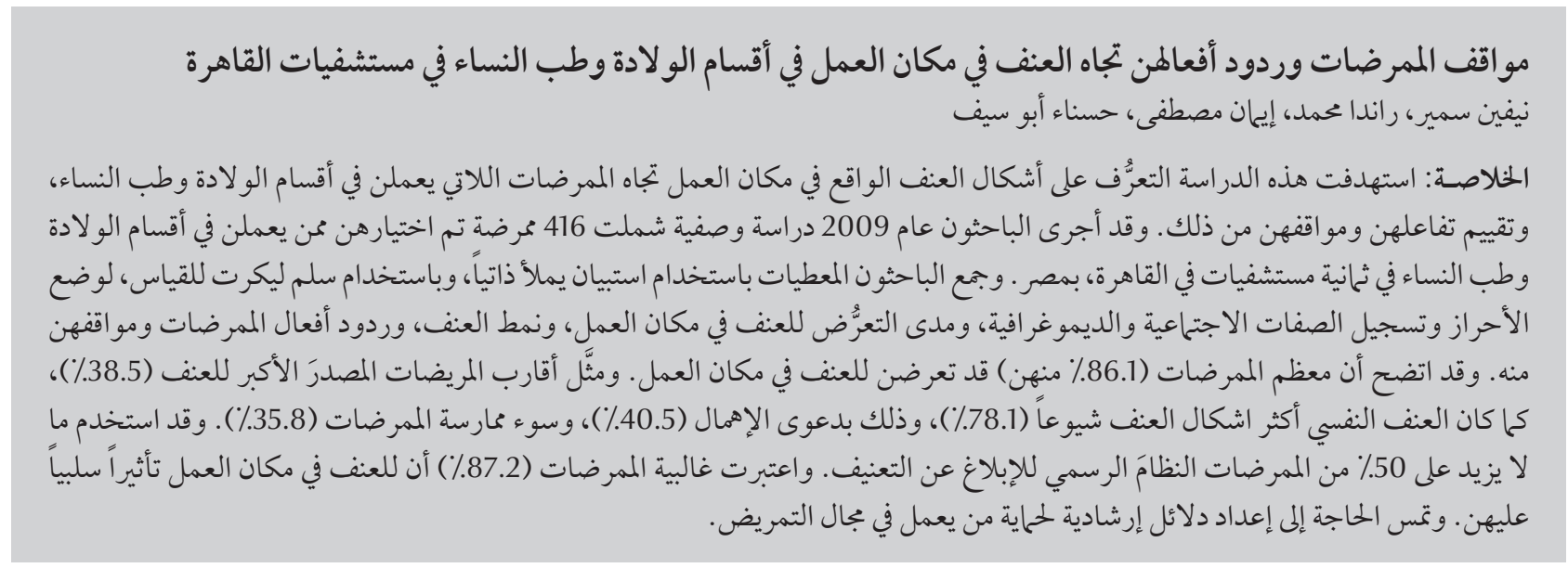

ABSTRACT This study aimed to identify forms of workplace violence against obstetrics and gynaecology nurses and assess their reaction and attitude to it. A descriptive cross-sectional study was conducted in 2009 among 416 randomly selected nurses in obstetrics and gynaecology departments in 8 hospitals in Cairo, Egypt. Data were collected using a self-completed questionnaire and Likert scale to record sociodemographic characteristics, exposure to workplace violence and its types, and nurses' reaction and attitude to it. The majority of nurses (86.1\%) had been exposed to workplace violence. Patients' relatives were the greatest source of violence (38.5\%) and psychological violence was the most common form (78.1\%). Carelessness (40.5\%) and malpractice of nurses $(35.8 \%)$ were reported as the usual causes of violence. For psychological and physical violence $<50 \%$ of the nurses used the formal system to report abuse. Most nurses (87.2\%) considered workplace violence had a negative effect of on them. Guidelines for protection of nursing staff are needed.

Attitudes et réactions du personnel infirmier face à la violence dans les services d'obstétrique et de gynécologie d'hôpitaux du Caire

RÉSUMÉ La présente étude visait à identifier les formes de violence au travail dirigées contre le personnel infirmier des services d'obstétrique et de gynécologie, à évaluer leur attitude et à comprendre leur réaction. Une étude descriptive transversale a été menée en 2009 auprès de 416 membres du personnel infirmier des services d'obstétrique et de gynécologie sélectionnés aléatoirement dans huit hôpitaux du Caire (Égypte). Les données ont été recueillies à l'aide d'un auto-questionnaire et de l'échelle de Likert. Les caractéristiques sociodémographiques des répondants, leur exposition à la violence au travail et ses différentes formes, leur attitude ainsi que leur réaction ont été enregistrées. La majorité de ce personnel $(86,1 \%)$ avait été exposée à la violence au travail. La famille des patients représentait la principale source de violence $(38,5 \%)$ alors que la violence psychologique était la forme la plus fréquente $(78,1 \%)$. La négligence $(40,5 \%)$ et les fautes professionnelles $(35,8 \%)$ étaient signalées comme des motifs classiques d'actes de violence. Dans les cas de violences psychologiques et physiques, les membres du personnel infirmier étaient moins de $50 \%$ à avoir recours au système formel de notification des abus, même s'ils étaient 87,2 \% à penser que cette violence au travail avait un effet négatif sur eux. Des recommandations sont nécessaires pour protéger le personnel infirmier. 


\section{Introduction}

Today, there is increasing evidence of nursing staff being exposed to violent behaviour in the workplace; indeed, it is now considered a major occupational hazard worldwide [1-4].

Workplace violence has many forms according to the definition of the World Health Organization (WHO) and may include physical assault, homicide, verbal abuse, bullying/mobbing, sexual and racial harassment, and psychological stress. The United States National Institute for Occupational Safety and Health defines workplace violence as violent acts, including physical assaults, directed towards a person at work or on duty [5]. Violence is present in all work environments but nurses are on the frontline of the health care system and have the closest contact with patients and their relatives. Thus they are at greatest risk of being abused in the hospital environment [5]. Physical abuse is reported to occur within health care facilities 4 times more often than all other industries combined [6].

Abusive behaviour in the work place has many negative impacts both at the individual and organizational level, such as decreased job performance and job satisfaction [7]. Indeed, workplace violence in the health sector is "so toxic that nurses increasingly report that it is one reason they abandon active practice" [8].

Sources of violence against nurses include patients, patients' relatives, peers, supervisors, subordinates and other professional groups [9]. The increase in violence by patients and their families in health care settings can be seen as a type of "ward rage" precipitated by frustration and dissatisfaction with the quality of care received. Such abusive behaviour contributes to the high rates of nurse burn-out [10]. Several factors are reported to be associated with an increased risk of violence at the workplace, both at the individual and organizational level, such as such as younger age [11], medical department $[12]$ and understaffing $[13,14]$.

One study in Egypt reported the negative impact of violence against nurses working in obstetric and gynaecological departments including job dissatisfaction, poor performance, and high turnover rates [15]. However, there are otherwise few articles and documented data on the prevalence and forms of workplace violence toward nurses working at obstetric and gynaecological departments. Therefore the aim of this study was to identify forms of workplace violence toward nurses working at obstetric and gynaecological departments and assess the nurses' attitudes and reactions to different types of workplace violence.

\section{Methods}

\section{Study design and period}

This was a descriptive cross-sectional study conducted from 1 April 2008 to 30 April 2009.

\section{Study setting and sample}

There are 87 hospitals in total in Cairo city in Egypt listed by the Ministry of Health (MOH), 73 multispecialty hospitals and 14 single specialty hospitals. The latter were excluded as they do not have obstetrics and gynaecology services. The remaining 73 multispecialty hospitals fall into 6 categories: 10 university hospitals, 4 teaching hospitals, 6 health insurance hospitals, 6 treatment agencies (type of hospital under the $\mathrm{MOH}$ in Cairo), 7 government hospitals and 40 private hospitals. We selected 2 hospitals randomly from each category (12 hospitals in total) and 8 agreed to participate in the study. The 8 hospitals included were: Ain Shams Maternity University Hospital (university hospital), Specialized Cairo and Cleopatra hospitals (private hospital), El Galaa and Ahmed Maher hospitals (teaching hospital), East Nasser City Hospital (health insurance hospital), Heliopolis hospital (treatment agency) and Dar El Shefa (government hospital).

The sample size was calculated based on the following assumptions: $30 \%$ estimated prevalence of violence against nurses [15],95\% desired level of confidence and 5\% acceptable margin of error. The formula used yielded a sample size of 323 nurses. As the sample selection was stratified (first a representative selection of hospitals) and not simple random, the sample size was increased by 1.5 to 484 nurses to correct for this difference in design. The sample was further increased by 5\% to account for contingencies such as non-response, bringing the final sample size to 500 nurses. The total sample was distributed among the 8 hospitals and sample proportion and weighting was done. Nurses working in obstetric and gynaecological departments in various inpatient and outpatient clinics of the selected hospitals were selected randomly.

All 500 nurses agreed to participate in the study but only 416 of them completed the questionnaire and Likert scale and returned them

\section{Data collection tools}

An structured questionnaire in Arabic and a 3-point Likert scale were used for data collection. We developed these after reviewing the relevant literature. The items included in the tools were reviewed by an expert panel for appropriateness and ability to measure the concepts to assure content validity of the scale and questionnaire. The expert panel consisted of nursing administrators and faculty of nursing professors in specialized in maternity care. A pilot study was conducted with 20 randomly selected nurses, excluded from the main study, and based on face and content validity some questions were modified and others dropped on questionnaire (30 statements, Cronbach alpha $=$ 0.742 ) while some statements were rephrased and others dropped on the 
Likert scale (8 statements, Cronbach alpha $=0.766)$.

The structured questionnaire consisted of 2 parts. Part I dealt with sociodemographic characteristics of nurses. Part II focused on nurses experience of violence to themselves, its forms, causes, sources and their reactions to the violence.

The Likert scale was adapted from Punnett et al. (2007) [16] and was modified by the researchers to assess the nurses' attitude toward the work place violence. It consisted of 8 statements, each statement had 3 responses (agree, uncertain, disagree, scored 3, 2 , and 1 respectively). The response scores for each statement and for all statements were summed for all and each nurse and the total divided by the number of responding nurses to get a mean score for each statement and for the total score. A total score of $>16 / 24$ was taken to indicate that the nurse's attitude was affirmative towards the adverse effects of violence while a score of $<16$ was taken to indicate the nurse's attitude was negative to the adverse effects of violence.

\section{Data collection}

Official permission was obtained from the administration of the selected hospitals after reviewing ethical aspects of the study. Data were collected 3 days/ week over the study period. The purpose of the study was explained to the selected nurses and their agreement to participate was obtained. Nurses were informed them that they had right to refuse participation in the study with no repercussions. In all hospitals there was an assistant from the nursing supervisor was allocated to help with data collection. The questionnaires (in sealed envelopes) were left with the supervisors of the departments to give to other nurses in other shifts to complete. Confidentiality of the data was assured by collection of the completed questionnaires by the researchers which were in sealed envelopes. Only the researchers then had access to the data.

\section{Data analysis}

Data were analysed using SPSS, version 18. Frequency and percentage distributions, and mean and standard deviation were calculated. A liner regression analysis were done (with Cochrane test) and to determine the independent predictors of nurses' attitude to workplace violence.

\section{Results}

Table 1 shows that almost half the nurses were aged 20 to 29 years and only $3.8 \%$ were over 40 years. As regards qualification, $47.6 \%$ had a diploma while $35.6 \%$ had a bachelor degree, and $47.6 \%$ were single and $48.1 \%$ married. A quarter of the nurses worked in government hospitals. Approximately half (49.0\%) of the nurses had less than 3 years workplace experience and $24.5 \%$ worked in the operating room and $29.8 \%$ in the delivery room, which are particularly demanding departments.

Table 2 shows that the majority of the nurses (86.1\%) had been exposed to violence at work in the past 6 months, with about 53\% having been exposed to violence 3 or more times in that period. For $54.5 \%$ of the nurses the abuse came from medical or administrative colleagues/staff members while for $38.5 \%$, patients'

\begin{tabular}{|c|c|c|}
\hline Characteristic & No. $(n=416)$ & $\%$ \\
\hline \multicolumn{3}{|l|}{ Age (years) } \\
\hline$<20$ & 120 & 28.8 \\
\hline $20-29$ & 202 & 48.6 \\
\hline 30-39 & 78 & 18.8 \\
\hline$\geq 40$ & 16 & 3.8 \\
\hline \multicolumn{3}{|l|}{ Educational level } \\
\hline Diploma & 198 & 47.6 \\
\hline Associated degree & 70 & 16.8 \\
\hline Bachelor degree & 148 & 35.6 \\
\hline \multicolumn{3}{|l|}{ Marital status } \\
\hline Single & 198 & 47.6 \\
\hline Married & 200 & 48.1 \\
\hline Widowed & 8 & 1.9 \\
\hline Divorced & 10 & 2.4 \\
\hline \multicolumn{3}{|l|}{ Type of hospital } \\
\hline Government & 106 & 25.4 \\
\hline Private & 70 & 16.8 \\
\hline University & 82 & 19.7 \\
\hline Teaching & 68 & 16.3 \\
\hline Treatment agency & 36 & 8.6 \\
\hline Health insurance & 54 & 13.0 \\
\hline \multicolumn{3}{|c|}{ Experience in work place (years) } \\
\hline$<3$ & 204 & 49.0 \\
\hline $3-5$ & 120 & 28.8 \\
\hline$>5$ & 92 & 22.1 \\
\hline \multicolumn{3}{|c|}{ Place of work in hospital } \\
\hline Inpatient unit & 130 & 31.3 \\
\hline Operating room & 102 & 24.5 \\
\hline Outpatient clinic & 60 & 14.4 \\
\hline Delivery room & 124 & 29.8 \\
\hline
\end{tabular}




\begin{tabular}{|c|c|c|}
\hline Variable & No. $(n=416)$ & $\%$ \\
\hline \multicolumn{3}{|l|}{ Experienced violence in past 6 months } \\
\hline No & 58 & 13.9 \\
\hline Yes & 358 & 86.1 \\
\hline \multicolumn{3}{|l|}{ Number of times violence experienced in past 6 months } \\
\hline None & 58 & 13.9 \\
\hline$<3$ & 137 & 32.9 \\
\hline 3 & 134 & 32.2 \\
\hline$>3$ & 87 & 20.9 \\
\hline \multicolumn{3}{|l|}{ Type of violence ${ }^{a, b}$} \\
\hline Psychological & 325 & 78.1 \\
\hline Physical & 113 & 27.2 \\
\hline Sexual & 19 & 4.6 \\
\hline \multicolumn{3}{|l|}{ Cause of violence $e^{a, b}$} \\
\hline Lateness coming to shift ${ }^{\mathrm{c}}$ & 68 & 19.0 \\
\hline Carelessness/malpractice $^{c}$ & 128 & 35.8 \\
\hline Increased workload/shortage of nurses leading to delays in care provided & 145 & 40.5 \\
\hline Stressful events ${ }^{d}$ & 28 & 7.8 \\
\hline No apparent cause & 18 & 5.0 \\
\hline \multicolumn{3}{|l|}{ Source of violence $e^{a, b}$} \\
\hline Patient & 61 & 14.7 \\
\hline Relatives of patient & 160 & 38.5 \\
\hline Others on the medical team & 105 & 25.2 \\
\hline Administrative team of the department & 122 & 29.3 \\
\hline
\end{tabular}

${ }^{a}$ Not mutually exclusive: more than one answer was reported because all episodes of violence experienced by the nurses were included.

${ }^{b}$ In the past 6 months.

'On the part of the nurse.

${ }^{d}$ Experienced by the perpetrator of violence against the nurse.

relatives were the source of violence. Psychological violence was the most common type of violence reported (78.1\%) and $27.2 \%$ had been exposed to physical violence. Increased workload and shortage of nurses was cited as the reason behind the violence by $40.5 \%$ of nurses, while $35.8 \%$ mentioned carelessness and malpractice of nurses (both represented the main causes of violence toward nurses).

Table 3 indicates that for nurses who reported experiencing psychological violence, $72.9 \%$ reported verbal abuse as the most common form of psychological violence while $62.8 \%$ of the nurses reporting physical violence, mentioned being pushed and slapped as a form of physical violence. About half of the nurses (49.7\%) formally reported violence against them.
Table 4 shows that the majority of nurses (87.2\%) exposed to workplace violence agreed that it had a negative effect on nurses. Only $0.05 \%$ did not think it had an adverse effect.

Table 5 shows that there was a highly statistically significant difference in the nurses' reaction to the different types of violence. For all types of violence using a formal system of reporting was the most common reaction to workplace violence.

The significant independent positive predictors of nurses' attitude score towards workplace violence were: exposure to violence $(\beta=0.421)$, years of experience in the workplace $(\beta=$ $0.045)$, all kinds of violence except sexual violence $(\beta$ for psychological $=0.370$, $\beta$ for physical $=0.050)$, and all sources of violence except patient's relative ( $\beta$ for patient $=0.238, \beta$ for medical team $=0.178$ and $\beta$ for administrative team $=$ 0.209) (Table 6). Use of formal system as reaction to exposure to violence was a negative predicator of attitude score ( $\beta$ $=-0.147)$. The model explained $20.6 \%$ of the variation in nurses' attitude score towards workplace violence $\left(r^{2}=20.6\right.$, $P=0.001)$.

\section{Discussion}

Our study showed that the majority of nurses had been exposed to violence and most of them had been exposed to violence more than once in the past 6 months. Psychological violence was the most common type of violence experienced with over three-quarters 


\begin{tabular}{lcc}
\hline $\begin{array}{l}\text { Table } 3 \text { Forms of different types of violence toward studied nurses and their } \\
\text { reaction to violence }\end{array}$ & No. \\
\hline Variable & 237 & 72.9 \\
Psychological violence & 88 & 27.1 \\
$\quad$ Verbal abuse & & \\
$\quad$ Disrespect by ignoring nurse's presence & 42 & 37.2 \\
Physical violence & 71 & 62.8 \\
$\quad$ Physical abuse with an instrument & \\
$\quad$ Pushing and slapping & 19 & 100.0 \\
Sexual violence & & \\
$\quad$ Harassment & 44 & 12.3 \\
Nurses' reaction to violence & 37 & 10.3 \\
$\quad$ Silence/acceptance & 99 & 27.7 \\
$\quad$ Anger \& resignation & 178 & 49.7 \\
$\quad$ Anger but continue working & & \\
$\quad$ Use formal system &
\end{tabular}

${ }^{a}$ Such as scissors, forceps, etc.

of the sample reporting exposure to this type of violence. Verbal abuse was the most common form of psychological violence, while pushing \& slapping was the most common form of physical violence. This finding is in line with other studies that found most nurses had experienced psychological violence followed by physical violence $[9,10]$. Our study showed that nurses with less than 3 years work experience were more likely to be exposed to violence than nurse with longer work experience. This finding agrees with a Jordanian study which found shorter professional nursing experience was significantly associated with a higher risk of all type of violence in the workplace [17].
We found that patient's relatives were the most usual source of violence against nurses, followed by members of administrative and medical teams. This finding is in disagreement with other studies which found that the major sources of workplace violence was patients themselves (62.8\%) followed by relatives (16.7\%) and few colleagues and administrative staff or supervisors committed the abuse. This may due to the low nurse-to-patient ratio and nursing shortages in our hospitals, which may lead to decreased patient stay time and lack of adequate nursing care which may precipitate abuse from patients or their relatives $[18,19]$.

The present study revealed that $40.5 \%$ of the nurses thought that increased workload and shortage of nursing staff was the main cause of violence and more than a third considered that malpractice was the cause of violence. This may suggest limited experience and poor nursing training among the nurses or limited opportunity to enhance specialty nursing skills but these findings disagree with a Caribbean study which found that the causes of assault by relatives of patients was related to anger at enforcement of hospital policies or were related to the patient's condition (57\%), and anger related to the health care system in general (46.5\%) [16].

Half of the nurses in our study used the formal hospital system against abusers as a reaction to violence, but almost a third of the sample had an angry reaction and either resigned or did nothing. Most of the nurses felt that violence threatened the dignity of the nurses and affected both their quality of work and their relationship with work colleagues. These findings concur with other studies which concluded that the most common reactions against abusive behaviour were anger, helplessness, humiliation and depression $[9,20]$.

In our study, less than half the nurses reported psychological and physical violence through the formal system ( $42 \%$ and $48 \%$ respectively) while almost $90 \%$ reported sexual violence. Other studies have reported that two-thirds of verbal abuse and half of physical violence were

\begin{tabular}{lccc}
\hline Table 4 Nurses' ' attitude toward workplace violence $(\boldsymbol{n = 4 1 6 )}$ & & & \\
\hline Attitude & Disagree \% & Uncertain \% & Agree \% \\
Workplace violence threats nurses' dignity & 1.7 & 14.7 & 83.6 \\
Verbal violence is more damaging than physical violence & 1.7 & 14.7 & 83.6 \\
Verbal violence is more damaging than sexual violence & 5.3 & 8.7 & 86.0 \\
Violence has psychosocial consequences that threaten nurses' entity & 2.4 & 6.7 & 90.9 \\
Violence affects nurses' behaviour & 2.9 & 8.2 & 88.9 \\
Violence affects nurses' quality of work & 11.5 & 18.1 & 70.4 \\
Violence affects nurses' relationships with their work colleagues & 9.1 & 17.3 & 73.6 \\
Violence increases turnover in nursing staff & 10.3 & 21.2 & 68.5 \\
Total mean score & 0.5 & 12.3 & 87.2 \\
\hline
\end{tabular}




\begin{tabular}{|c|c|c|c|c|c|c|}
\hline \multirow[t]{3}{*}{ Nurses' reaction to violence } & \multicolumn{6}{|c|}{ Type of violence } \\
\hline & \multicolumn{2}{|c|}{ Psychological $(n=325)$} & \multicolumn{2}{|c|}{ Physical $(n=113)$} & \multicolumn{2}{|c|}{ Sexual $(n=19)$} \\
\hline & No. & $\%$ & No. & $\%$ & No. & $\%$ \\
\hline Silence \& acceptance & 42 & 12.9 & 10 & 8.8 & 0 & 0.0 \\
\hline Anger \& leave work & 34 & 10.5 & 24 & 21.2 & 2 & 10.5 \\
\hline Anger but continue working & 96 & 29.5 & 25 & 22.1 & 0 & 0.0 \\
\hline Use formal system & 135 & 41.5 & 54 & 47.8 & 17 & 89.5 \\
\hline$P$-value ${ }^{a}$ & \multicolumn{2}{|c|}{0.001} & \multicolumn{2}{|c|}{0.001} & \multicolumn{2}{|c|}{0.001} \\
\hline Cochrane Q & \multicolumn{2}{|c|}{112.477} & \multicolumn{2}{|c|}{36.274} & \multicolumn{2}{|c|}{42.684} \\
\hline
\end{tabular}

${ }^{a}$ Comparing nurses' reaction to different types of violence.

not reported by nurses $[17,20]$. It is not really clear why nurses do not report abuse; it may be due to the fact that the forma system is time-consuming or that the hospital lacks a formal system for reporting violence, or, as reported in an Iranian study [21], it may be because organizations do not take action when verbal abuse does occur this perpetuating the problem. Consequently, nurses continue to accept verbal abuse as they feel that they do not have the power to change it. It may also be because nurses still believe that "assaults are part of the job" and they are reluctant to take action after an assault.

The present study revealed that the majority of nurses (87.2\%) who were exposed to violence believed that workplace violence had a negative effect of on their work and may lead to increased errors and decreased quality of care as well as decreased job satisfaction. In addition to the effect of workplace violence on a nurse's personal life, it can create a hostile environment for the nurse and lead to isolation. The predictors of nurses' attitude score toward workplace violence were exposure to violence, years of experience in the workplace, all kind of violence except sexual violence, and all source of violence except patient's relatives. This is similar to other studies of the association between nurses' attitude and different sources of violence against them $[22,23]$.
While some hospitals did not agree to participate in the study and some nurses dropped out as a result of the sensitivity of the topic, none the less a large number of nurses did respond and the results provide useful insight into the problem of workplace violence in obstetric and gynaecological departments in Cairo hospitals.

\section{Conclusions}

We conclude that there is a high rate of violence against nurses in obstetric and gynaecological departments in the hospitals studied and it affects the majority of nurses. The majority of the nurses believed workplace violence had

\begin{tabular}{lcccc}
\hline Table 6 Liner regression analysis for nurses' ${ }^{\prime}$ attitude scores toward workplace violence & & \\
\hline Item & Beta & $\boldsymbol{t}$ & $\boldsymbol{P}$-value & $\mathbf{9 5 \%} \mathbf{C l}$ \\
Exposed to violence & 0.421 & 4.766 & 0.001 & 0.247 to 0.594 \\
Years of experience in the workplace & 0.045 & 2.160 & 0.031 & 0.004 to 0.087 \\
Kind of violence: psychological & 0.370 & 5.395 & 0.001 & 0.235 to 0.505 \\
Kind of violence: physical & 0.050 & 1.985 & 0.048 & 0.000 to 0.099 \\
Kind of violence: sexual & 0.049 & 1.892 & 0.059 & -0.002 to 0.100 \\
Nurse's reaction to violence: silent \& accept & -0.062 & -1.187 & 0.236 & -0.165 to 0.041 \\
Nurse's reaction to violence: anger \& leave work & -0.050 & -0.802 & 0.423 & -0.174 to 0.073 \\
Nurse reaction to violence: use formal system & -0.147 & -3.505 & 0.001 & -0.230 to -0.065 \\
Source of violence: patient & 0.238 & 3.476 & 0.001 & 0.103 to 0.372 \\
Source of violence: relative(s) of patient & 0.078 & 1.463 & 0.144 & -0.027 to 0.182 \\
Source of violence: other on medical team & 0.178 & 3.057 & 0.002 & 0.064 to 0.292 \\
Source of violence: administrative team of agency & 0.209 & 3.190 & 0.002 & 0.080 to 0.337 \\
Constant & 2.166 & 27.027 & 0.001 & 2.008 to 2.323 \\
\hline
\end{tabular}

$r=45.4, r^{2}=20.6, F=8.715, P$-value $=0.001$.

$\mathrm{Cl}=$ confidence interval. 
negative effect of on nurses' work and personal life.

Given this high rate of workplace violence and relatively low rate of reporting of violence incidents, hospitals should develop effective guidelines to restrict workplace violence and protect nursing staff in maternity departments, such as a mandatory incident reporting system, review of security teams' responsibilities, and incident follow-up by management. Educational seminars for nurses are recommended that focus on communication techniques and stress or anger management with conflict resolution to effectively manage violence in the workplace.

\section{Acknowledgements}

This research would not have been possible to complete without the cooperation and support of the nurses who participated in this study and the administrative personnel at the selected Egyptian hospitals.

\section{References}

1. Kwak P et al. Prevalence of workplace violence against nurses in Hong Kong. Hong Kong Medical Journal, 2006, 12:6-9.

2. Framework guidelines for addressing work place violence in the health sector. Geneva, World Health Organization, 2002:3

3. Canarino $\mathrm{D}$ et al. Work-related factors and violence among nursing staff in the European NEXT study: a longitudinal cohort study. International Journal of Nursing Studies, 2008, 45:35-50.

4. Hegney D et al. Workplace violence in Queensland, Australia: The results of a comparative study. International Journal of Nursing Practice, 2006, 12:220-231.

5. American Association of Colleges of Nursing. Position statement. Violence as a public health problem. Journal of Professional Nursing, 2000, 16:63-69.

6. Yusuf C, Sevilay S. Sexual harassment against nurses in Turkey. Journal of Nursing Scholarship, 2007, 39:200-206.

7. Lin $\mathrm{Y}$, Liu $\mathrm{H}$. The impact of workplace violence on nurses in South Taiwan. International Journal of Nursing Studies, 2005, 42:773-778.

8. DiMartino V. Workplace violence in the health sector: Country case studies - Synthesis Report. Geneva, International Labour Office, 2002.

9. Lyneham J. Violence in NSW emergency departments. Australian Journal of Advanced Nursing, 2000, 18:8-17.

10. Salim M, Kamalc N, Al-Raqemc M. Violence against nurses in healthcare facilities in Kuwait. International Journal of Nursing Studies, 2002, 39:469-478.

11. Cooper CL, Swanson N. Workplace violence in the health sector: State of the Art. Geneva, International Labour Organization, World Health Organization, International Council of Nurses and PSI, 2002.

12. Ortega A et al. Prevalence of workplace bullying and risk groups. a representative population study. International Archives of Occupational and Environmental Health, 2009, 82:417-426.
13. Lewis MA. Nurse bullying, organizational considerations in the maintenance and perpetration of health care bullying cultures. Journal of Nursing Management, 2006, 14:52-58.

14. Gerberich $\mathrm{S}$ et al. An epidemiological study of the magnitude and consequences of work related violence: The Minnesota Nurses' Study. Occupational and Environmental Medicine, 2004, 61:495-503.

15. Abbas MA et al. Epidemiology of workplace violence against nursing staff in Ismailia Governorate, Egypt. Journal of the Egyptian Public Health Association, 2010, 85(1-1):29-43

16. Punett B, Greenidge D, Ramsey J. Job attitudes and absenteeism: A study in the English speaking Caribbean. Journal of World Business, 2007, 42:214-227.

17. Oweis A. Jordanian nurses perception of physicians' verbal abuse: findings from a questionnaire survey. International Journal of Nursing Studies, 2005, 42:881-888.

18. Trish W. The escalating trend of violence toward nurses. Journal of Emergency Nursing, 2008, 34:130-133.

19. Abid SM et al. Violence against nurses in healthcare facilities in Kuwait, International Journal of Nursing Studies, 2002, 39(4):469-478.

20. O'Brien-Pallas L et al. Creating work environments that are violence free. World Hospitals and Health Services, 2009, 45:12-18.

21. Esmaeilpour M, Salsali M, Ahmadi F. Workplace violence against Iranian nurses working in emergency departments. International Nursing Review, 2011, 58:130-137.

22. Kisa S. Turkish nurses' experiences of verbal abuse at work. Archives of Psychiatric Nursing, 2008, 22:200-207.

23. Lavan W. Workplace bullying: A review of litigated cases. Employee Responsibilities and Rights Journal, 2009, 10:9140-9144. 